EPiC Series in Engineering
Volume 3, 2018, Pages 1682-1691
HIC 2018. 13th International
Conference on Hydroinformatics

\title{
Reservoir monitoring using satellite SAR and GNSS: a case study in southern Italy
}

\author{
Claudia Pipitone ${ }^{1,3 *}$, Francesca Cigna ${ }^{2 \dagger}$, Gino Dardanelli1 ${ }^{1 *}$, Goffredo La \\ Loggia $^{1 \S}$, Antonino Maltese ${ }^{1 * *}$ and Jan-Peter Muller ${ }^{3 \dagger \dagger}$ \\ ${ }^{1}$ Dipartimento di Ingegneria Civile Ambientale, Aerospaziale, dei Materiali (DICAM), Università \\ degli Studi di Palermo, Bld. 8, Viale delle Scienze, Palermo, 90128, Italy. \\ ${ }^{2}$ Italian Space Agency (ASI), Via del Politecnico snc, 00133 Rome, Italy. \\ ${ }^{3}$ Mullard Space Science Laboratory (MSSL), Department of Space \& Climate Physics, University \\ College London (UCL), Holmbury St. Mary, Surrey RH5 6NT, United Kingdom. \\ claudia.pipitone02@unipa.it, francesca.cigna@asi.it, \\ gino.dardanelli@unipa.it, goffredo.laloggia@unipa.it, \\ antonino.maltese@unipa.it, j.muller@ucl.ac.uk
}

\begin{abstract}
Recently, it has been demonstrated that it is possible to relate water levels of a reservoir with its dam displacements. Water levels were determined via remote sensing, while dam displacements were measured via Global Navigation Satellite System (GNSS). Results have shown that displacements and water levels are correlated.

Water levels at the Magazzolo reservoir in southern Italy were firstly retrieved using two remote sensing approaches: by visual matching between the reservoir shoreline and contour lines, and by evaluating the surface extent via unsupervised classification to estimate the water levels with an area/depth relation. Dam displacements were measured using GPS receivers on the dam and a permanent station from a GNSS Continuously Operating Reference Stations (CORS) network, about 30 kilometers away.

Subsequently, two other remote sensing approaches were tested to detect reservoir levels; the first based on shape similarity indices, while the second on the evaluation of the average distance between a reservoir shoreline and contour levels. First results were extracted from a Landsat 8 optical image acquired during a clear sky day.
\end{abstract}

\footnotetext{
* Performed GNSS and Interferometric SAR analyses, wrote and approved the paper

${ }^{\dagger}$ Performed Interferometric SAR analysis, wrote and approved the paper

‡ Performed GNSS and Interferometric SAR analyses, wrote and approved the paper

$\S$ Coordinated the research group, supervised the research, wrote and approved the paper

** Performed GNSS and Interferometric SAR analyses, wrote and approved the paper

${ }^{\dagger \dagger}$ Coordinated the research group, supervised the research, wrote and approved the paper
} 
Reservoir Monitoring Using Satellite SAR and GNSS: a Case Study in Southern ... C. Pipitone et al.

Within this work, algorithms for water level retrieval have been tested and validated under different conditions over a more consistent satellite dataset including Sentinel-1A Synthetic Aperture Radar (SAR) images acquired from October 2014 to September 2015. The dataset is also used to analyses dam displacements via Interferometric SAR (InSAR), to be compared with the effects of water level fluctuations on the dam. First results suggest that it is possible to correlate dam displacements and water levels derived by the same dataset. However, it is shown that displacements also depend on meteorological forcing.

\section{Introduction}

Satellite technologies allow the monitoring of dam displacements and reservoir water levels using different techniques and datasets. Several studies were recently conducted on the Castello embankment dam on the Magazzolo reservoir in Sicily (Italy) by analyzing the interaction between variables. Preliminary research pointed out the correlation between the dam displacements recorded using GNSS and water levels evaluated by means of Landsat 7 ETM+ SLC-Off optical images (Dardanelli, La Loggia, Perfetti, Capodici, Puccio, \& Maltese, 2014). Then, a comparison between GNSS displacements and conventional geodetic measures, hydraulics and geotechnical models was carried out (Dardanelli \& Pipitone, Hydraulic models and finite elements for monitoring of an earth dam, by using GNSS techniques, 2017). More recently both optical and SAR satellite images with different acquisition modes, geometric and spectral resolutions were used (Pipitone, Maltese, Dardanelli, Lo Brutto, \& La Loggia, 2018). Water levels were compared to GNSS displacements of the middle cross section of the dam, to analyses their relationship with water level fluctuations during emptying and filling periods. However, environmental factors, including the presence of clouds and shadows, reduce the number of samples available in the dataset of optical images and thus limit the operational applicability of the classification technique.

Recently, two other approaches were tested on a few optical images characterized by clear sky, clouds or shadows, and a COSMO-SkyMed SAR image (Pipitone, Maltese, Dardanelli, Capodici, Lo Brutto, \& La Loggia, 2017). These approaches are based on shape similarity indices (Shape, Theme, Edge and Position) (Lizarazo, 2014), and on a distance index.

In addition, several studies have shown the advantages of satellite InSAR to monitor dam movements (Lazecký, Perissin, Zhiying, Ling, \& Yuxiao, 2015) (Tomás, et al., 2013) (Sousa, Lazecký, Hlaváčová, Bakoň, Patricio, \& Perissin, 2015) (Lazecký, Perissin, Scaioni, Lei, \& Qin, 2003) (Milillo, et al., 2016) using different approaches and datasets, such as the study comparing displacements of a rock dam in Japan, by exploiting Differential InSAR (DInSAR) and GNSS, and revealing strong correlation with both ascending and descending orbits (Shimizu, 2015).

Within this work, the analyzed SAR dataset was enlarged to include 21 Single Look Complex (SLC) Sentinel-1A (S1A) SAR images, which were used to detect both the displacements of the dam via satellite InSAR and water levels of the reservoir by using different metrics. 


\section{Materials and Methods}

\subsection{Study Area}

The study area includes the Castello dam on the Magazzolo reservoir $\left(37^{\circ} 34^{\prime} 51^{\prime \prime} \mathrm{N}, 13^{\circ} 24^{\prime} 48^{\prime \prime} \mathrm{E}\right.$, WGS84) which is one of the main reservoirs in western Sicily, Italy. The analysis was conducted over a hydrological year from October 2014 to September 2015, during which the measured water levels $\left(H_{\mathrm{m}}\right)$ ranged from $281.47 \mathrm{~m}(06 / 11 / 2014)$ to $293.95 \mathrm{~m}(26 / 02 / 2015)$. The study area is represented in figure 1 using a S1A false-color composite to enhance the water level changes.

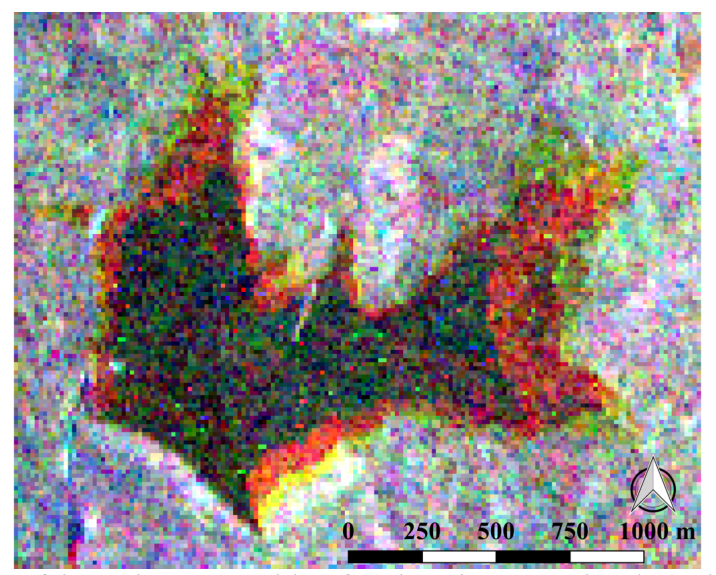

Figure 1: Diachronic S1A false-color composition for changing water levels (red channel: $H_{\mathrm{m}}=281.5 \mathrm{~m}$; green: $H_{\mathrm{m}}=288.7 \mathrm{~m}$; blue: $H_{\mathrm{m}}=293.7 \mathrm{~m}$ ).

\subsection{Previous findings and objectives}

The influence of water levels and air temperatures on displacements obtained from GNSS were shown (Pipitone, Maltese, Dardanelli, Lo Brutto, \& La Loggia, 2018) during the monitoring period from April 2011 to April 2012. Figure 2 shows that a maximum displacement of the dam occurred when the water level reached its minimum (20/10/2011). Another maximum displacement took place during the emptying period, when the daily average air temperature reached its maximum value (15/07/2011). Two values of minima displacements during the emptying and filling periods correspond to the maximum and minimum daily average air temperatures (21/08/2011 and 11/02/2012). 


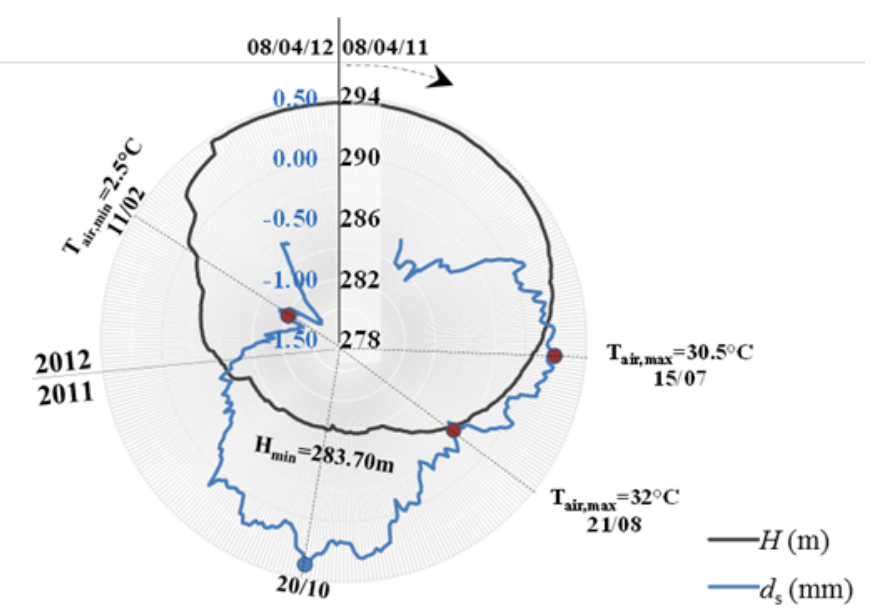

Figure 2: Relation between displacements, air temperatures, and water levels during the emptying and filling periods (Apr 2011 - Apr 2012). Rearranged and integrated from (Pipitone, Maltese, Dardanelli, Lo Brutto, \& La Loggia, 2018).

The research objective here is the determination of water levels and displacements with the same set of satellite images.

Following some preliminary analyses (Pipitone, Maltese, Dardanelli, Capodici, Lo Brutto, \& La Loggia, 2017), contour lines extracted from a LIDAR DEM at $2 \mathrm{~m}$ resolution have been used as a reference to determine water levels ranging from 281 to $294 \mathrm{~m}$. A total of 21 SAR images have been selected for this analysis in ascending orbits. All data have been acquired in SLC in Interferometric Wide (IW) swath mode at $5 \mathrm{~m}$ by $20 \mathrm{~m}$ spatial resolution.

\subsection{Water levels estimation}

Two different approaches have been tested for the water level estimation. The first is based on similarity metrics, while the second on the average distance of a shoreline with the contour levels. The analysis was carried out i) on an ideal case using a reference contour line as shoreline (Figure 3) and ii) on a few optical images and one COSMO-SkyMed image characterized by high surface roughness (Pipitone, Maltese, Dardanelli, Capodici, Lo Brutto, \& La Loggia, 2017). For the ideal case, all indices correctly identified the measured water level. Best results for the other images have been found for a clear sky Landsat 8 image. The Edge index $\left(S_{\mathrm{E}}\right)$ was particularly suitable to identify the closest contour lines to the reference boundary. The $\mathrm{S}_{\mathrm{E}}$ index compares the length of the boundaries of the classified shoreline and the perimeter of the reference objects (the contour lines). $S_{\mathrm{E}}$ can be evaluated using a distance corresponding to the maximum error at a specific confidence level (the epsilon distance, $\varepsilon$ ) (Lizarazo, 2014). Within the ideal case, $\varepsilon$ was ranging between 0 and half the spatial resolution of the DEM. 


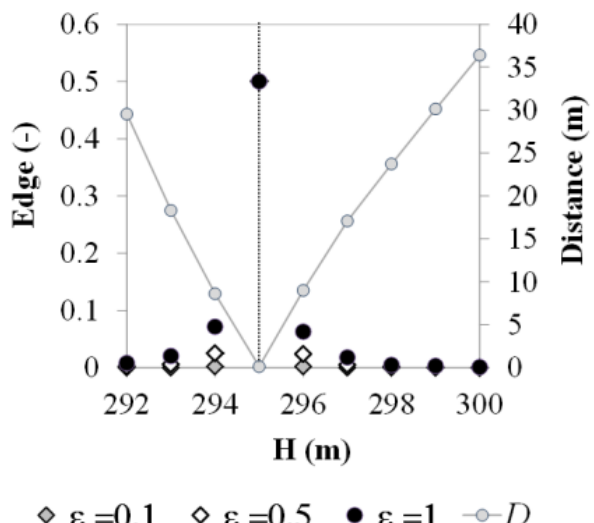

Figure 3: Edge (on primary axis) and average distance (on secondary axis) indices on the ideal case.

Initially, all SLC images were calibrated using the European Space Agency's Sentinel Application Platform (SNAP) software. After applying multi-look processing, pixels were aggregated to $28 \mathrm{~m}$ spatial resolution. Then, the water surface extent was identified using an unsupervised classification technique and both the STEP algorithm and a method based on average distance from a reference object, implemented within Geographical Information System (GIS) software, were applied.

\subsection{Dam displacements estimation}

Dam displacements were estimated using an advanced multi-temporal InSAR technique performed with SARProZ (C) software (Perissin, 2009-2017). This technique is based on the identification of persistent scatterers in the SAR amplitude images throughout the dataset, by combining spatially and temporally all slave images with a master reference image using a star graph. Within this study, the master image (10/06/2015) takes a barycenter position within the distribution of normal and temporal baselines. Then, a reference point is selected to evaluate the interferometric phase of all persistent scatterers within the study area.

\section{Results and discussion}

\subsection{Reservoir water levels}

Despite the high accuracies reached when tested on the ideal case, both approaches applied on SLC backscattering images have shown some inconsistencies. Anyway, these look comparable to the spatial resolution of the reference DEM.

Results for the three selected images acquired with minimum, intermediate and maximum water levels $\left(H_{\mathrm{m}}=281.5 \mathrm{~m} ; 288.7 \mathrm{~m}\right.$ and $293.7 \mathrm{~m}$ respectively) are shown in figure 4 . 
Reservoir Monitoring Using Satellite SAR and GNSS: a Case Study in Southern ... C. Pipitone et al.
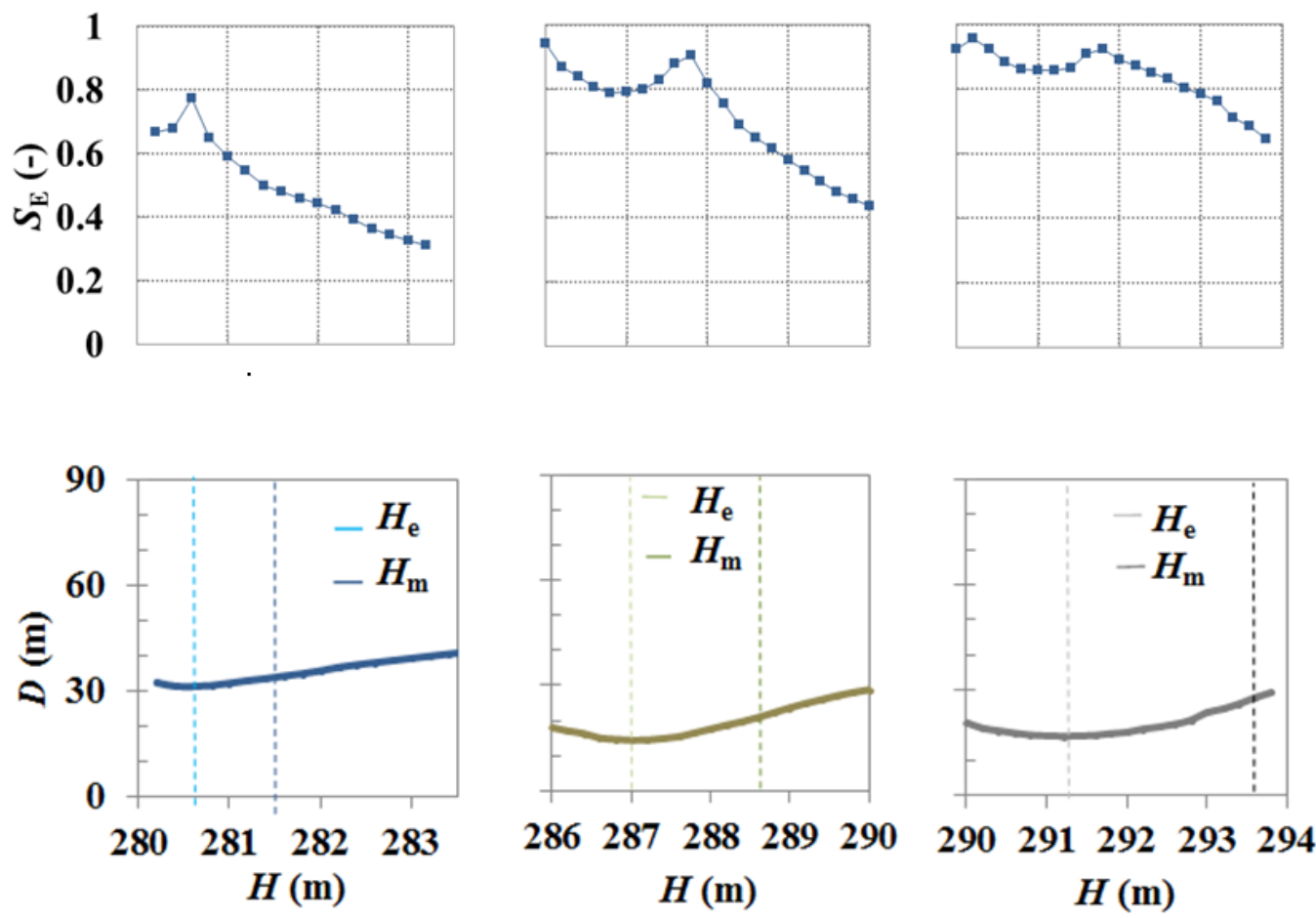

Figure 4: Edge index ( $S_{\mathrm{E}}$, upper panels) calculated with $\varepsilon=14 \mathrm{~m}$ and average distance index $(D$, lower panels) for a minimum, average and maximum water level $(06 / 11 / 2014$ on the left, 09/08/2015 in the center, $18 / 03 / 2015$ on the right, respectively).

The difference between measured and evaluated water levels using both techniques is less than one meter for the lowest water level $(06 / 11 / 2014)$ and less than 3 meters for the other two images (Table 1). Results show also that the epsilon distance $(\varepsilon)$ has an influence on the identification of water levels. In this study, two different values of $\varepsilon$ are compared, represented by half of the DEM resolution $(2 \mathrm{~m})$ and half of the pixels resolution after aggregation $(28 \mathrm{~m})$.

\begin{tabular}{ccccc}
\hline Date & $H_{\mathrm{m}}(\mathrm{m})$ & $\begin{array}{c}H S_{\mathrm{E}}(\mathrm{m}) \\
\varepsilon=1 \mathrm{~m}\end{array}$ & $\begin{array}{c}H S_{\mathrm{E}}(\mathrm{m}) \\
\varepsilon=14 \mathrm{~m}\end{array}$ & $H_{\mathrm{D}}(\mathrm{m})$ \\
\hline $06 / 11 / 2014$ & 281.5 & 280.6 & 280.6 & 280.6 \\
$18 / 03 / 2015$ & 293.7 & 291.2 & 291.8 & 291.2 \\
$09 / 08 / 2015$ & 288.7 & 286.8 & 287.8 & 287.0
\end{tabular}

Table 1: Comparison between measured water levels and water levels obtained from Edge $\left(H_{\mathrm{S}}\right)$ metric and the average distance $\left(H_{\mathrm{D}}\right)$. 


\subsection{Dam displacements}

After the co-registration of all the slave images with the master and other pre-processes (including reflectivity map and amplitude stability index calculation, preliminary geocoding, coherence estimation and interferogram processing) over a wide area, a small area comprising the dam was selected for the analysis. The star graph shows a low coherence of the normal and temporal baselines connected to the master image. The Atmospheric Phase Screen (APS) has been estimated via the inverted residuals approach, using as input parameter to detect the points to be analyzed the Amplitude Stability Index (ASI) with a given threshold. The Inverted parameter approach, available in SARProZ, forces the solution even though it returns a higher coherence. External services, such as the Generic Atmospheric Correction Online Service for InSAR - GACOS (http://cegresearch.ncl.ac.uk/v2/gacos/) are currently not supported, although an import of external APS delay maps could be implemented in the SARProZ open source code.

Figure 5 shows the average amplitude of all the images, the so called "reflectivity map". This map is analyzed over the small area, which includes the reservoir and a small area surrounding it, wide enough to include a reference persistent scatterer.

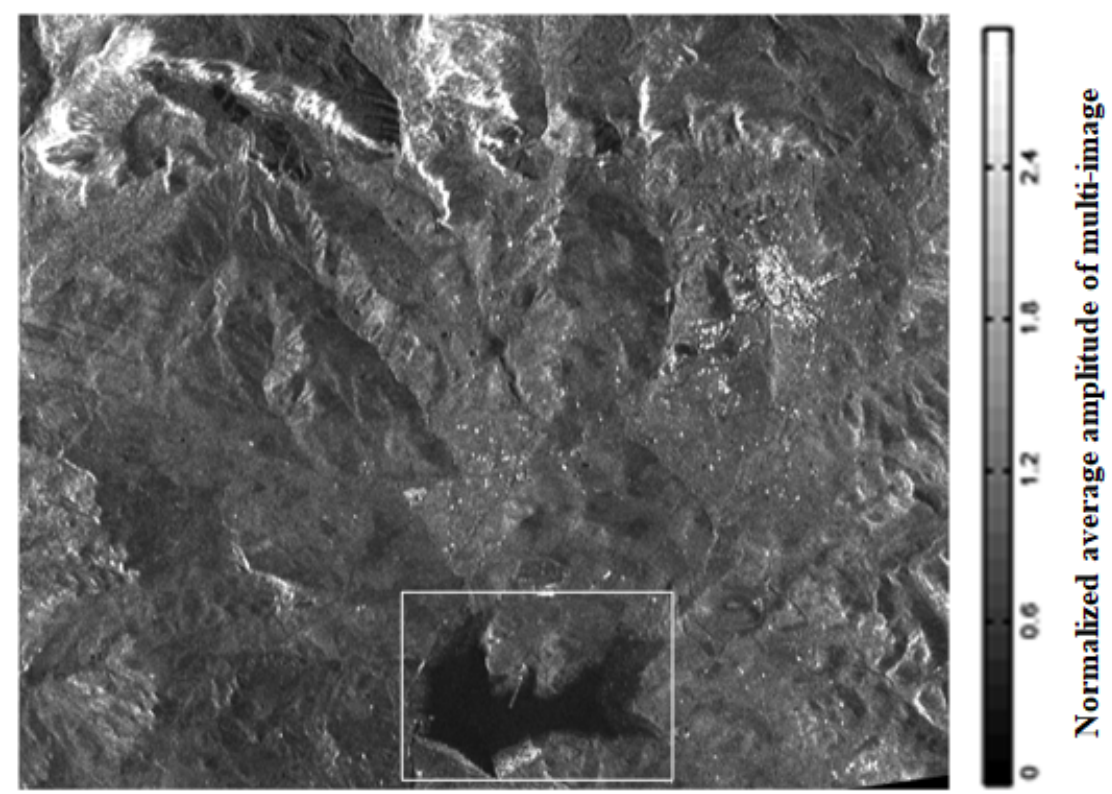

Figure 5: S1A SAR reflectivity map of the study area (displayed in SARProZ $C$ ). The white box highlights the Magazzolo reservoir.

The reflectivity map highlights that the left bank of the dam, and the dam itself are characterized by an average-high level of amplitude during the whole time series. 


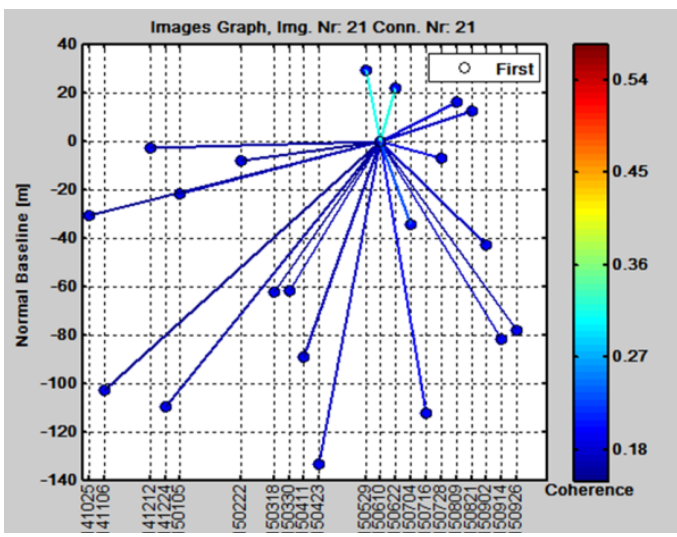

Figure 6: Star-graph Multi-Image InSAR processing (25 October 2014 - 26 September 2015).

Figure 6 shows the acquisition time (in x-axis) versus the normal baseline (m) in y-axis, where the master image is at the center of the star, thus giving a general overview of the temporal and spatial baselines for the chosen master. The coherence of each slave image with the master image is represented through a color scale.

Figure 7 shows the phase interferograms for the whole dataset; of course an interferogram could be quite clean (as in this case) when the slave has a small temporal baseline with the master, while it loses correlation when the temporal baseline increases too far.

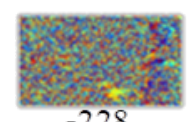$$
-228
$$

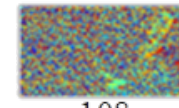

$-108$

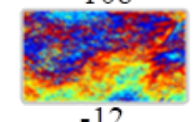

$-12$

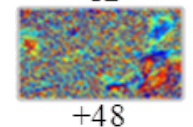

$+48$

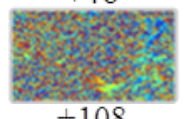

$+108$

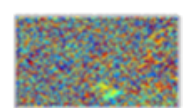

$-216$

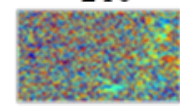

$-84$
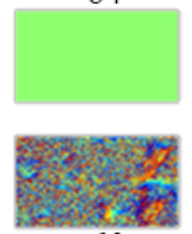

$+60$

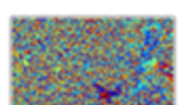

$-180$

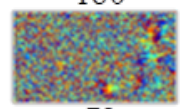

$-72$

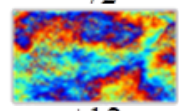

$+12$

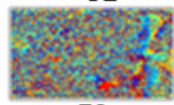

$+72$

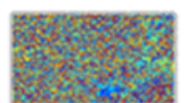

$-168$

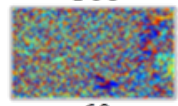

$-60$

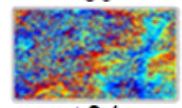

$+24$

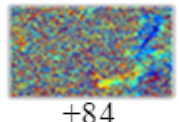

$+84$

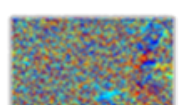

$-156$

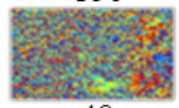

$-48$

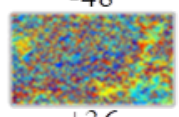

$+36$

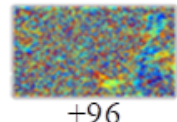

Figure 7: S1A interferograms of the whole dataset referred to the master image (10/06/2015) within the small area. The value underneath each image indicates the number of days from the acquisition of the master (in green).

The Multi-Image Processing for the small area allows an estimation of the linear trend and the height of selected points within the scene, referred to the reference point with high spatial and temporal coherence.

Results have also shown the capabilities of the technique to detect many points on the dam with high reflectivity, especially on the left side that is made of stones. Displacements have been calculated only along the satellite line of sight (LOS) because only images acquired on ascending orbit have been analyzed. 
Figure 8 shows a geocoded map of cumulative displacements around the study area. Vertical and horizontal components of the displacements will be calculated in future once scenes acquired in descending orbits are processed. Then, displacements of the dam will be compared with the water level of the reservoir to confirm retrievals reported in (Pipitone, Maltese, Dardanelli, Lo Brutto, \& La Loggia, 2018).

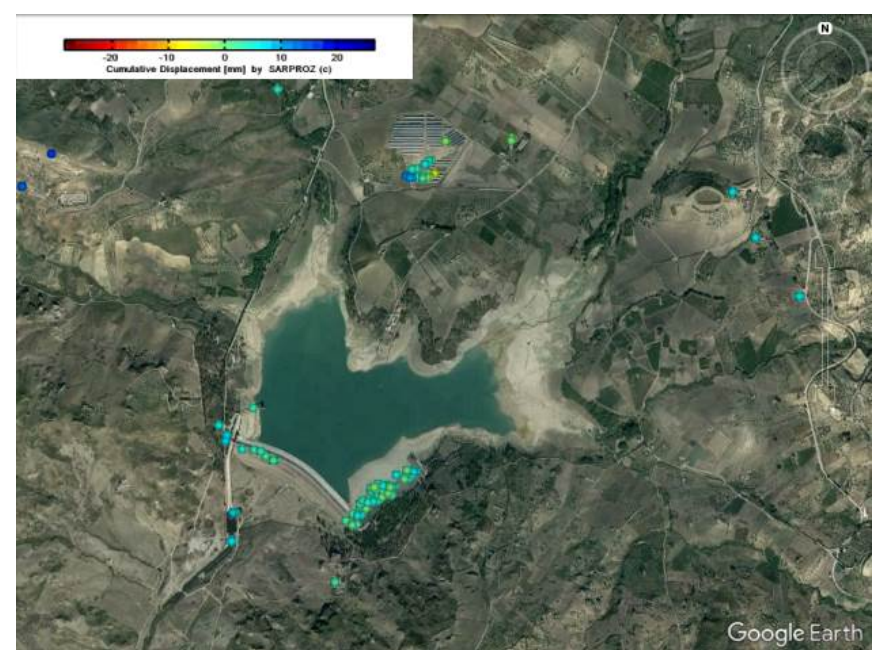

Figure 8: Cumulative displacements (25 October 2014 - 26 September 2015) of S1A persistent scatterers.

\section{Conclusions}

Results suggest that the same SAR dataset can be used to retrieve both water levels via shape similarity metrics or a distance index, and dam displacements, using the InSAR technique. Using a dataset including S1A SAR images acquired from October 2014 to September 2015, better estimates of water levels have been obtained via the edge similarity index. Results have also demonstrated the capabilities of InSAR techniques for dam monitoring. Further analyses are required to determine horizontal and vertical displacements of the dam, to be compared with the effects of water level fluctuations on the dam.

\section{Acknowledgments}

The authors would like to thank the European Space Agency (ESA) for providing the Sentinel-1A images. The authors thank the Mullard Space Science Laboratory (MSSL), University College London (UCL) for hosting C. Pipitone as visiting scientist from September 2017 to February 2018. The software used in this work is SARProZ $\mathbb{C}$, developed by D. Perissin. The authors are grateful to the developer also for his technical support. 


\section{References}

Dardanelli, G., \& Pipitone, C. (2017). Hydraulic models and finite elements for monitoring of an earth dam, by using GNSS techniques. Period. Polytech. Civ. Eng., 61, 421- 433.

Dardanelli, G., La Loggia, G., Perfetti, N., Capodici, F., Puccio, L., \& Maltese, A. (2014). Monitoring displacements of an earthen dam using GNSS and remote sensing. Proceedings of SPIE Vol. 9239, (p. 923928).

Lazecký, M., Perissin, D., Scaioni, M., Lei, L., \& Qin, Y. (2003). Plover Cove Dam Monitoring with Spaceborne InSAR Technique in Hong Kong. Proceedings of the 2nd Joint International Symposium on Deformation Monitoring (JISDM). Nottingham, UK, 9-10 September.

Lazecký, M., Perissin, D., Zhiying, W., Ling, L., \& Yuxiao, Q. (2015). Observing Dam's Movements with Spaceborne SAR Interferometry. In: Lollino G., Manconi A., Guzzetti F., Culshaw M., Bobrowsky P., Luino F. (eds) Engineering Geology for Society and Territory - Volume 5. Springer, Cham, (p. 131-136).

Lizarazo, I. (2014). Accuracy assessment of object-based image classification: another STEP. International Journal of Remote Sensing, 35(16), 6135-6156.

Milillo, P., Tapete, D., Cigna, F., Perissin, D., Salzer, J., Lundgren, P., et al. (2016). Structural health monitoring of engineered structures using space-borne synthetic aperture radar multitemporal approach: from cultural heritage sites to war zones. Proceedings of SPIE 10003, (p. $100030 \mathrm{~N})$.

Perissin, D. (2009-2017). SARPROZ Manual, Copyright (c) . http://www.sarproz.com/softwaremanual/.

Pipitone, C., Maltese, A., Dardanelli, G., Capodici, F., Lo Brutto, M., \& La Loggia, G. (2017). Detection of a reservoir water level using shape similarity metrics. Proceedings of SPIE Vol. 10421, (p. 104211L).

Pipitone, C., Maltese, A., Dardanelli, G., Lo Brutto, M., \& La Loggia, G. (2018). Monitoring Water Surface and Level of a Reservoir Using Different Remote Sensing Approaches and Comparison with Dam Displacements Evaluated via GNSS. Remote Sens., 10(1), 71.

Shimizu, N. (2015). Rock Displacement Monitoring using Satellite Technologies-GPS and InSAR. Proceedings of the ISRM VietRock International Workshop. Hanoi, Vietnam, 12-13 March.

Sousa, J. J., Lazecký, M., Hlaváčová, I., Bakoň, M., Patricio, G., \& Perissin, D. (2015). Satellite SAR interferometry for monitoring dam deformations in Portugal. Second International Dam World Conference, , (p. 1-8). Lisbon, Portugal, April 21-24.

Tomás, R., Cano, M., García-Barba, J., Vicente, F., Herrera, G., Lopez-Sanchez, J. M., et al. (2013). Monitoring an earthfill dam using differential SAR interferometry: La Pedrera dam, Alicante, Spain. Engineering Geology, 157, 21-32. 